\title{
Analisis Efektifitas Penggunaan Metode Soft Starter saat Start awal pada pengoperasian Motor $220 \mathrm{~kW}$
}

\author{
Andi Junaidi'; Susan Damayanti² \\ ${ }^{1}$ Sekolah Tinggi Teknik PLN \\ ${ }^{2}$ Universitas Jenderal Achmad Yani \\ ${ }^{1}$ andi.junaidi@sttpln.ac.id \\ ${ }^{2}$ ssndamayanti@gmail.com
}

\begin{abstract}
The Multipurpose Reactor G.A Siwabessy is a research reactor equipped with a Cooling System consisting of 2 systems, namely the primary cooling system and the secondary cooling system. This Project discusses the effectiveness of using the Soft starter method in the initial starting process of the electric motor in the secondary cooling system which aims to reduce the value of a high current surge when the motor starts working. The data type used is primary data obtained directly by the author through a measurement process with a measuring instrument. When using the Star-Delta method the surge current is $765 \mathrm{~A}$ while with the Soft starter method there is a decrease in the current surge value to $517 \mathrm{~A}$, the conclusion of the result is a decrease in the current surge value of $0,677 \%$ using the Soft starter method.
\end{abstract}

Keywords: Motor, Secondary system, Soft starter, Star-Delta

\begin{abstract}
ABSTRAK
Reaktor Serba Guna G.A Siwabessy merupakan reaktor riset yang dilengkapi dengan Sistem Pendingin yang terdiri dari 2 sistem, yaitu sistem pendingin primer dan sistem pendingin sekunder. Penelitian ini membahas mengenai efektifitas penggunaan metode Soft starter dalam proses starting awal motor listrik di sistem pendingin sekunder yang bertujuan untuk mengurangi nilai lonjakan arus yang tinggi saat awal motor mulai bekerja. Tipe data yang digunakan adalah data primer yang diperoleh langsung oleh penulis melalui proses pengukuran dengan alat ukur. Saat menggunakan metode Star-Delta lonjakan arus berada di angka 765 A sedangkan dengan metode Soft starter terjadi penurunan nilai lonjakan arus menjadi 517 A, kesimpulan dari hasil tersebut adalah terjadi penurunan nilai lonjakan arus sebesar 0,67\% dengan menggunakan metode Soft starter.
\end{abstract}

Kata kunci: Motor, Sistem sekunder, Soft starter, Star-Delta 


\section{PENDAHULUAN}

Dalam melaksanakan tugasnya Reaktor Serba Guna G.A Siwabessy merupakan reaktor riset yang dilengkapi dengan Sistem Pendingin yang terdiri dari 2 sistem, yaitu sistem pendingin primer dan sistem pendingin sekunder. Sistem Pendingin Primer berfungsi mengambil panas dari hasil reaksi fisi yang berlangsung di teras reaktor, sedangkan Sistem Pendingin Sekunder berfungsi mangambil panas dari sistem pendingin primer untuk selanjutnya panas tersebut dibuang ke udara luar melalui menara pendingin (cooling tower) [1]. Pada sistem pendingin sekunder terdapat 3 buah motor pompa yaitu PA-01 AP001, PA-02 AP001 dan PA-03 AP001, dua buah motor pompa untuk operai normal dan satu buah motor pompa sebagai cadangan. Motor induksi yang umum digunakan ada dua jenis yaitu motor induksi satu fasa dan tiga fasa. Dalam pengoperasian nya, sistem pendingin sekunder menggunakan tiga buah motor induksi jenis tiga fasa [4]. Dalam pengoperasiannya sebelumnya, saat motor masih dioperasikan dengan metode Star-Delta terdapat beberapa kendala yaitu besarnya arus start awal yang mengakibatkan masa kerja motor listrik berkurang karena lonjakan arus yang tinggi membuat motor menjadi cepat rusak. Namun saat ini dua buah motor sudah dioperasikan menggunakan metode Soft starter. Fungsi dari metode Soft starter ialah menurunkan nilai lonjakan arus saat start motor [2]. Dalam jurnal ini akan dibahas mengenai efektifitas penurunan arus menggunakan metode start awal Soft Starter dibandingkan dengan metode Star-Delta. Analisis dilakukan pada motor pompa PA - 02 AP001 dan PA - 03 AP001 di sistem pompa pendingin sekunder, menggunakan alat ukur Power Quality Analyzer (PQA) merk HIOKI 3169 - 20 Clamp On Power HiTester dan perangkat lunak HIOKI 9625 Power Measurement Support Software [5].

\section{METODE/PERANCANGAN PENELITIAN}

\subsection{Metode Star-Delta}

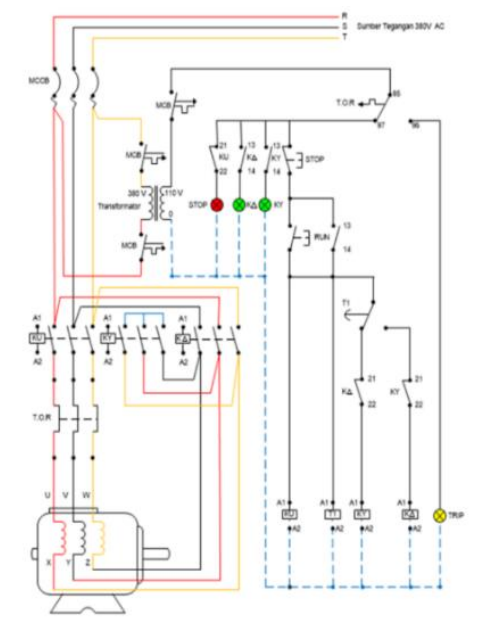

Gambar 1. Diagram Rangkaian Daya metode Star-Delta [3]

Metode start ini dapat mengurangi arus start dan torsi start. Umumnya peralatan ini terdiri dari 3 kontaktor yaitu relay beban lebih, dan timer untuk setting waktu dalam posisi star. Pada waktu start, yakni pada saat stator berada pada rangkaian bintang, arus motor hanya mengambil sepertiga dari arus motor seandainya motor di start dengan metode DOL. Namun karena torsi motor berbanding lurus dengan kuadratis dari tegangan maka dengan demikian torsi motor pada rangkaian bintang pun hanya sepertiga dari torsi pada rangkaian delta. Untuk mencapai kecepatan nominal, 
diperlukan perpindahan ke posisi delta, dimana hal ini mengakibatkan transmisi dan arus yang tinggi. Untuk beberapa kasus arus puncak dapat lebih tinggi dari start DOL. Bila torsi beban lebih besar 50\% dari torsi motor, metode Star-Delta tidak sanggup untuk menjalankan motor [3].

\subsection{Metode Soft Starter}

Soft Starter ialah metode yang digunakan untuk mengatur nominal arus start dari motor listrik. Prinsip kerjanya adalah dengan mengatur tegangan yang masuk ke motor. Pertama motor hanya diberikan tegangan yang rendah, sehingga arus dan torsi pun juga rendah. Pada level ini motor hanya sekedar bergerak perlahan dan tidak menimbulkan kejutan. Selanjutnya, tegangan akan dinaikkan secara bertahap sampai pada nominal tegangan nya dan motor akan berputar dengan kondisi RPM yang nominal. Komponen utama Soft Starter adalah thyristor dan rangkaian yang mengatur trigger thyristor. Seperti diketahui, output thyristor dapat diatur via pin gate nya. Rangkaian tersebut akan mengontrol level tegangan yang akan dikeluarkan oleh thyristor. Metode Soft Starting memiliki slip dan torsi paling rendah diantara metode yang lain pada keadaan tanpa beban maupun berbeban.

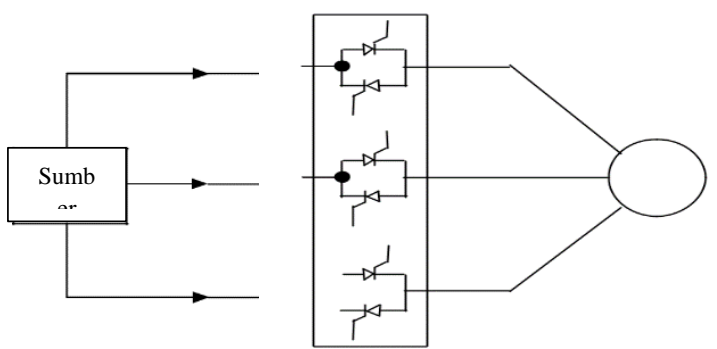

Gambar 2. Diagram Rangkaian Daya metode Soft starter [6]

Tegangan start dengan menggunakan metode Soft starter tidak tergantung pada arus yang ditarik oleh motor atau pada kecepatan motor, melainkan di program mengikuti kontur terhadap waktu (Time Voltage Ramp, TVR). Melalui TVR, pertama-tama motor hanya di berikan tegangan yang rendah sekitar 10\% - 70\% tegangan nominalnya sehingga arus dan torsi pun juga rendah. Pada level ini motor hanya sekedar bergerak perlahan dan tidak menimbulkan kejutan. Selanjutnya tegangan akan dinaikan secara bertahap sampai ke nominal tegangannya dan motor akan berputar dengan kondisi RPM yang nominal.

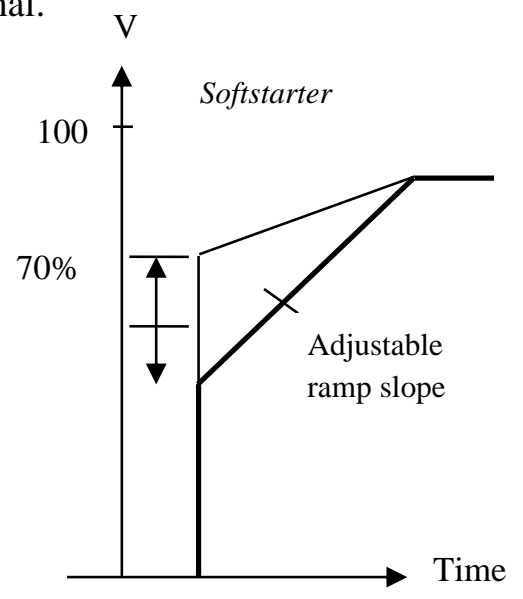


Gambar 3. Grafik ramp tegangan terhadap waktu [1]

Nilai daya, tegangan dan arus pada motor 3 fasa memiliki hubungan yang ditunjukkan dengan rumus dibawah ini:

$$
P=\sqrt{3} \cdot V \cdot I \cdot \cos \varphi
$$

Dimana:

$$
\begin{array}{ll}
\mathrm{P} & =\text { Daya Motor }(\mathrm{kW}) \\
\mathrm{V} & =\operatorname{Tegangan}(\mathrm{V}) \\
\mathrm{I} & =\text { Arus }(\mathrm{A}) \\
\operatorname{Cos} \varphi & =\text { Faktor daya }
\end{array}
$$

Sehingga untuk mendapatkan nilai arus dapat menggunakan rumus:

$$
I=\frac{P}{V} \cdot \sqrt{ } 3 \cdot \cos \varphi
$$

Nilai arus yang tertera pada nameplate adalah nilai arus nominal yang dapat dicari menggunakan rumus diatas, untuk mendapatkan nilai arus rata-rata dari nilai arus per-fasa maka digunakan rumus berikut:

$$
\mathrm{I}_{\text {rata-rata }}=\frac{\mathrm{IR}_{\mathrm{R}}+\mathrm{IS}_{\mathrm{S}}+\mathrm{IT}_{\mathrm{T}}}{3}
$$

Maka, untuk mendapatkan persentase penurunan nilai arus setelah menggunakan metode Soft Starter digunakan rumus seperti berikut:

$$
\% \text { Penurunan }=\frac{\mathrm{S} 1-\mathrm{S} 2}{\mathrm{~S} 1} \times 100 \%
$$

Dimana:

$\mathrm{S}_{1}=$ Nilai $\mathrm{I}_{\text {rata-rata }}$ saat menggunakan metode Star-Delta

$\mathrm{S}_{2}=$ Nilai I $\mathrm{I}_{\text {rata-rata }}$ saat menggunakan metode Soft starter

\subsection{Alat ukur}

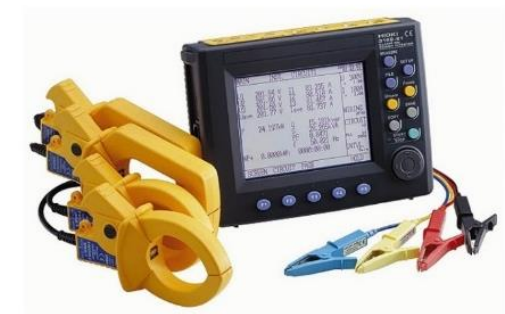

Gambar 4. HIOKI 3169 - 20 Clamp on power HiTester

Hioki 3169 - 20 Clamp on power HiTester merupakan alat ukur yang biasa digunakan dalam industri atau perusahaan besar, dapat mengukur hingga dua 3 - fasa, system 3 kawat. Alat ukur ini mampu melakukan pengukuran untuk menampilkan nilai arus, tegangan, daya, factor daya, dan frekuensi, daya aktif, daya reaktif, daya semu, nilai terpadu dan harmonisa. Nilai yang diukur tersebut dapat disimpan kedalam kartu memori yang terdapat dalam alat ini. Setelah dilakukan pengukuran hasilnya dapat dilihat dengan menggunakan software bawaan produk tersebut, hasil yang ditampilkan berupa grafik. [5] 


\section{HASIL DAN PEMBAHASAN}

\subsection{PA - 01 AP001}

Pada saat motor melakukan start awal dengan menggunakan metode Star-Delta terjadi lonjakan nilai arus yang tinggi, hal ini disebabkan karena motor induksi saat dihubungkan secara langsung dengan sumber tegangan akan menaikkan arus 500\% sampai 700\% dari nilai arus beban penuh. Arus mula yang besar ini dapat mengakibatkan pengurangan nilai (drop) tegangan pada saluran sehingga akan mengganggu peralatan lain yang dihubungkan pada saluran yang sama. Hasil pengujian yang dilakukan pada motor pompa PA - 01 AP001 yang masih menggunakan metode start dengan hubungan Star-Delta menunjukkan lonjakan arus yang tinggi seperti terlihat pada Gambar 5 (a), (b), dan (c) dibawah ini.

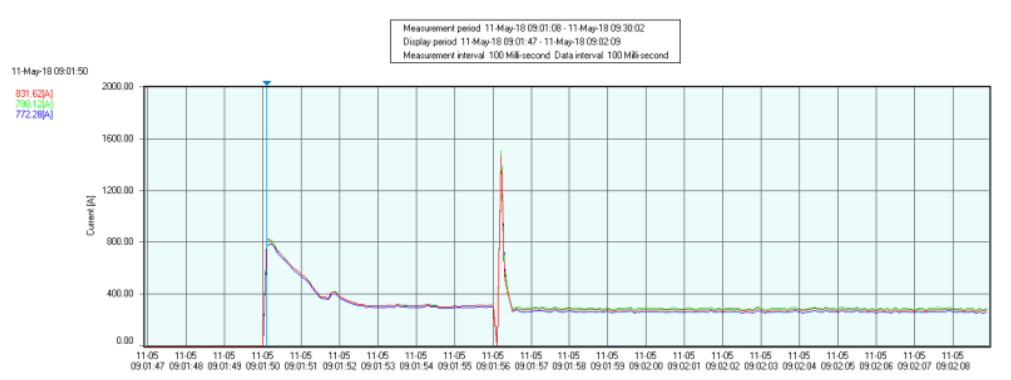

Gambar 5. (a) Tampilan grafik hasil pengukuran arus motor pompa PA - 01 AP001 posisi star

Pada gambar diatas terlihat saat posisi awal motor dihubung star/wye arus mengalami kenaikan dari 0 mencapai 831 A untuk fasa R, 798 A untuk fasa S dan 772 A untuk fasa T.

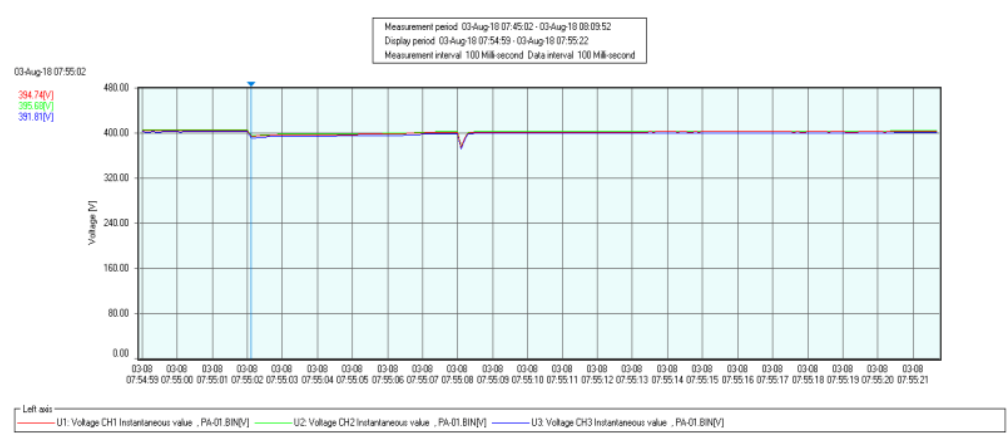

Gambar 5. (b) Tampilan grafik hasil pengukuran tegangan motor pompa PA - 01 AP001

Dari grafik dapat dilihat nilai tegangan saat awal penyalaan motor sebesar $402 \mathrm{~V}$ (nilai nominal), saat posisi star nilainya mengalami penurunan ke posisi $394 \mathrm{~V}$ untuk fasa R, 395 untuk fasa $\mathrm{S}$ dan 391 untuk fasa T, kemudian nilai tegangan kembali ke posisi nominal. Saat kondisi normal motor dihubung delta dan tegangan kembali turun ke posisi nilai 374 Vuntuk fasa R, 377 untuk fasa $\mathrm{S}$ dan 371 untuk fasa $\mathrm{T}$ dalam selang waktu 9 detik dari waktu awal penyalaan dan kembali lagi ke posisi nominalnya sebesar $402 \mathrm{~V}$. 


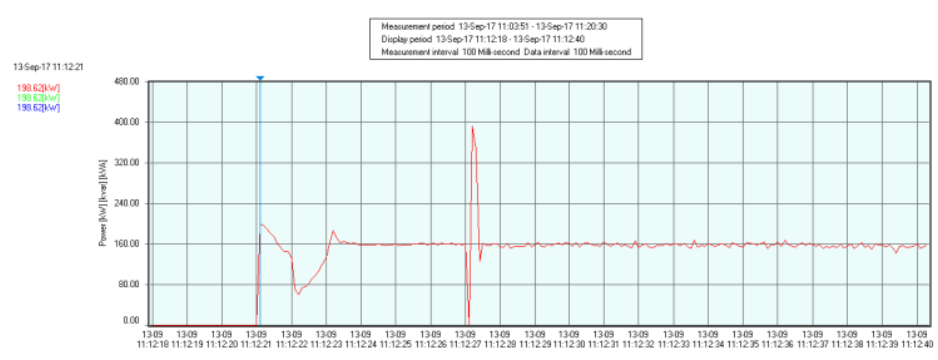

Gambar 5. (c) Tampilan grafik hasil pengukuran daya motor pompa PA - 01 AP001

Dari grafik diatas terlihat nilai daya yang masuk pada awal penyalaan motor hanya sebesar 38 $\mathrm{kW}$, kemudian naik secara bertahap mencapai nilai puncaknya sebesar $270 \mathrm{~kW}$ dalam selang waktu 5 detik dari waktu awal penyalaan motor, dan stabil pada posisi $210 \mathrm{~kW}$ dalam selang waktu 35 detik dari posisi terakhir.

\subsection{PA - 02 AP001}

Analisis selanjutnya dilakukan pada motor pompa PA - 02 AP001, motor ini sudah di modifikasi menggunakan metode Soft Starter untuk start awalnya. Dari grafik didapatkan hasil seperti gambar dibawah ini:

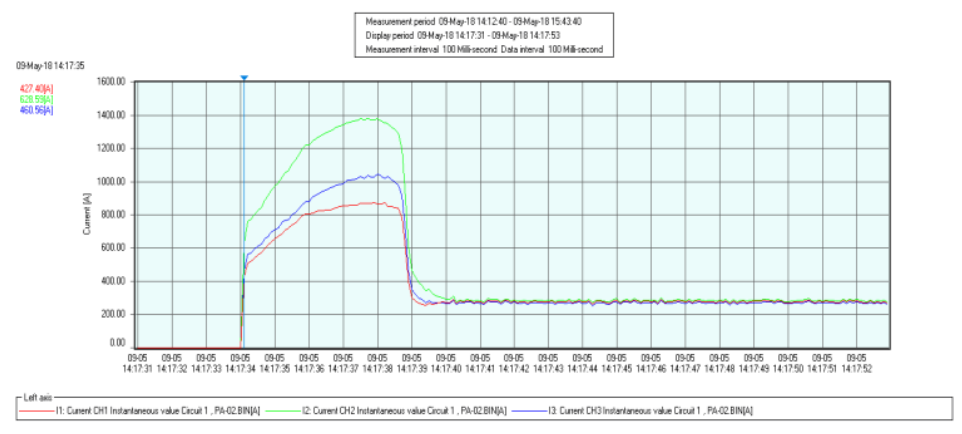

Gambar 6. (a) Tampilan grafik hasil pengukuran arus motor pompa PA - 02 AP001 posisi awal

Gambar grafik diatas menujukkan nilai arus start saat tegangan awal masuk, nilai arus naik dari posisi 0 ke nilai 427 A untuk fasa R, 628 untuk fasa S dan 460 A untuk fasa T.

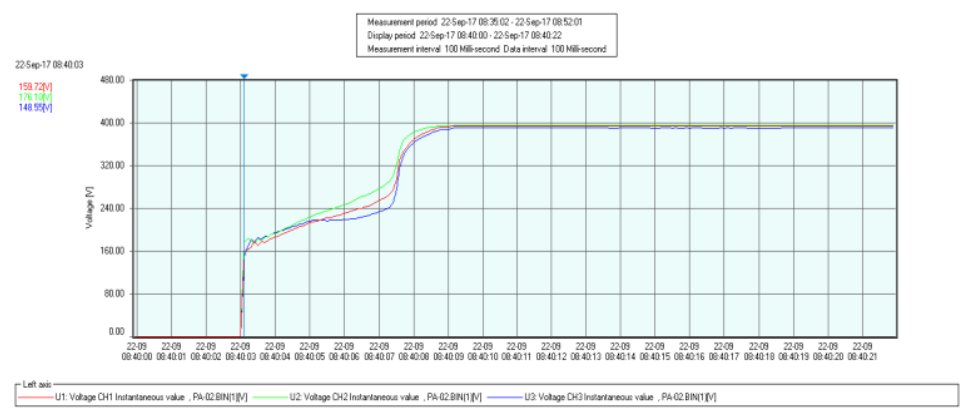

Gambar 6. (b) Tampilan grafik hasil pengukuran tegangan motor pompa PA - 02 AP001

Pengukuran pada tegangan ketika motor mulai bekerja nilai tegangan yang diberikan dinaikan secara bertahap dari posisi $0 \mathrm{~V}$, nilai tegangan yang diberikan pada awal penyalaan motor hanya sebesar $176 \mathrm{~V}$ atau sekitar $48 \%$ dari nilai nominal tegangan motor $400 \mathrm{~V}$, kemudian naik perlahan 
sampai mencapai nilai stabilnya yaitu $392 \mathrm{~V}$ untuk fasa R, $394 \mathrm{~V}$ pada fasa $\mathrm{S}$ dan 388 pada fasa T, nilai stabil tersebut tercapai dalam waktu 6 detik sejak awal motor dinyalakan.

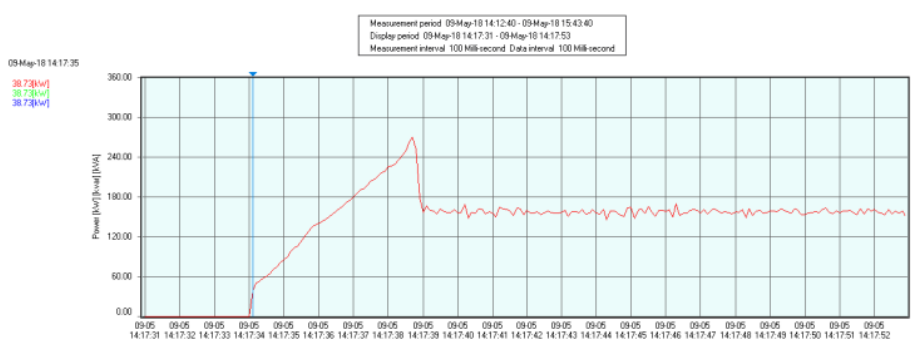

Gambar 6. (c) Tampilan grafik hasil pengukuran daya motor pompa PA - 02 AP001

Dari grafik diatas terlihat nilai daya yang masuk pada awal penyalaan motor hanya sebesar 38 $\mathrm{kW}$, kemudian naik secara bertahap mencapai nilai puncaknya sebesar $270 \mathrm{~kW}$ dalam selang waktu 5 detik dari waktu awal penyalaan motor, dan stabil pada posisi $210 \mathrm{~kW}$ dalam selang waktu 35 detik dari posisi terakhir.

\subsection{PA - 03 AP001}

Seperti hal nya motor pompa PA - 02 AP001, motor pompa PA - 03 AP001 ini pun sudah di modifikasi dengan metode Soft Starter, sehingga hasil grafik yang didapat pun akan relatif sama dengan motor pompa PA - 02 AP001, hanya ada sedikit perbedaan pada nominal nilai arus, tegangan dan daya nya yang tidak identik sama. Grafik pengukuran motor pompa PA - 03 AP001 ditunjukkan pada gambar dibawah ini:

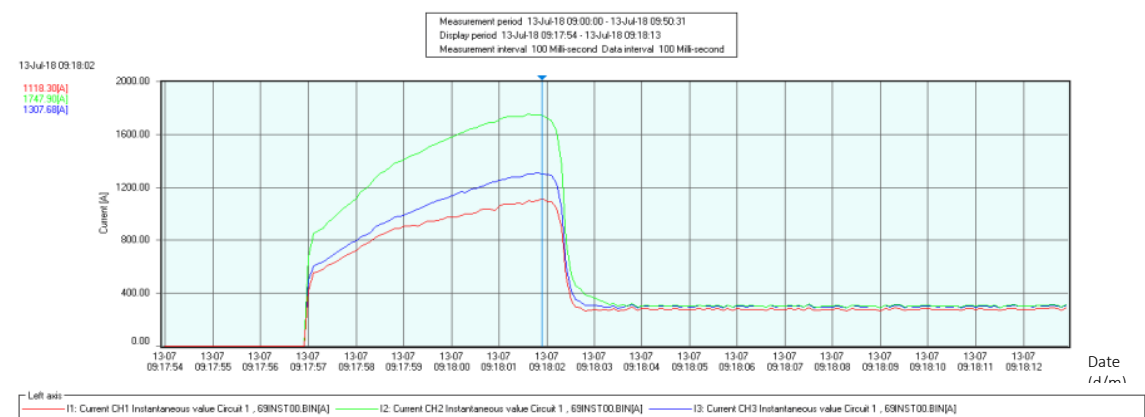

Gambar 7. (a) Tampilan grafik hasil pengukuran arus motor pompa PA - 03 AP001 posisi nilai puncak

Nilai arus naik bertahap dari posisi 0 A hingga 416 A untuk fasa R, 672 A untuk fasa S dan $500 \mathrm{~A}$ untuk fasa T. Kemudian nilai arus naik perlahan sampai mencapai nilai puncaknya sebesar 1118 A untuk fasa R, 1747 A untuk fasa S dan 1307 A untuk fasa T, yang dicapai dalam waktu 5 detik sejak awal motor digerakkan

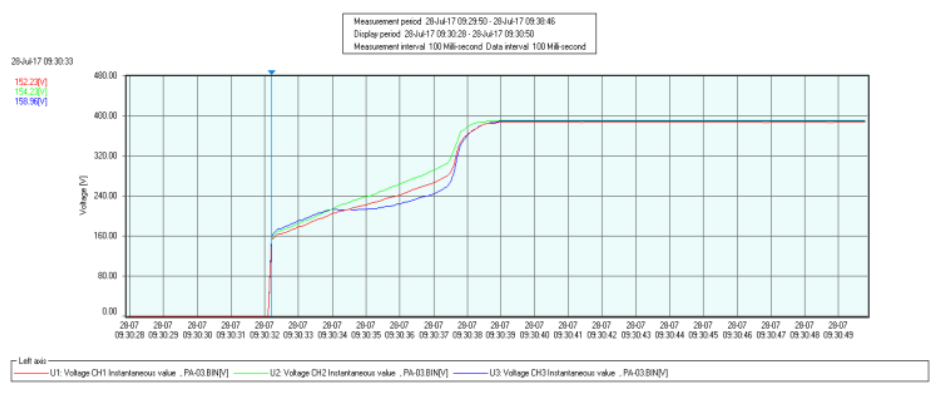


Gambar 7. (b) Tampilan grafik hasil pengukuran tegangan motor pompa PA - 03 AP001

Gambar 7 (b) menunjukkan hasil pengukuran tegangan motor pompa PA - 03 AP001. Tegangan motor yang diberikan pada saat penyalaan awal ialah sebesar $152 \mathrm{~V}$ untuk fasa $\mathrm{R}, 154 \mathrm{~V}$ untuk fasa $\mathrm{S}$ dan $158 \mathrm{~V}$ untuk fasa $\mathrm{T}$ atau sebesar $48 \%$ dari nilai nominal tegangan motor. Nilai ini akan naik perlahan sampai mencapai nilai stabilnya yaitu sebesar $388 \mathrm{~V}$ untuk fasa R, $391 \mathrm{~V}$ untuk fasa $\mathrm{S}$ dan $390 \mathrm{~V}$ untuk fasa $\mathrm{T}$, yang tercapai dalam selang dalam waktu 7 detik sejak motor mulai bergerak

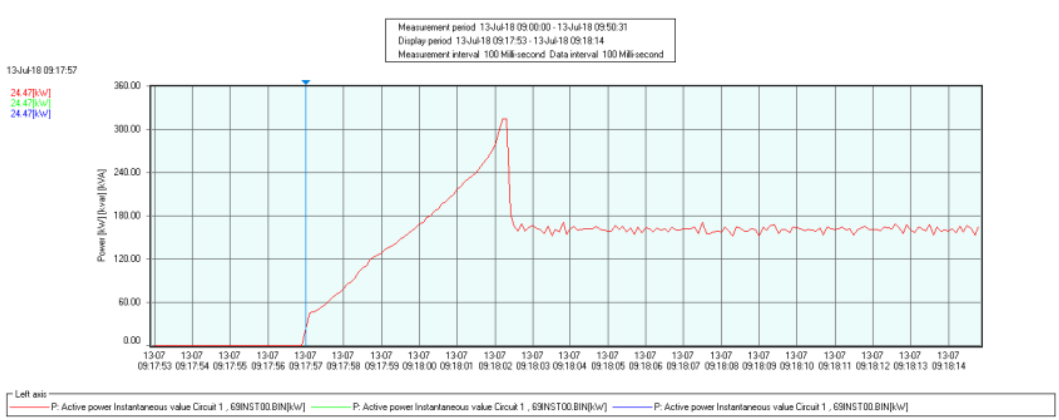

Gambar 7. (c) Tampilan grafik hasil pengukuran daya motor pompa PA - 03 AP001

Grafik pengukuran nilai daya ditunjukkan pada Gambar 7 (c) diatas. Grafik ini memiliki bentuk karakteristik grafik yang cenderung sama dengan grafik daya pada motor pompa PA - 02 AP001 hanya nilainya yang sedikit berbeda. Pada awal penyalaan motor daya yang diberikan hanya sebesar $24 \mathrm{~kW}$, kemudian mencapai nilai puncaknya sebesar $320 \mathrm{~kW}$ dalam selang waktu 5 detik dan mengalami penurunan sampai pada posisi stabilnya sebesar $200 \mathrm{~kW}$. Data hasil pengukuran arus, tegangan dan daya pada masing-masing motor tiap fasa nya dapat dilihat pada tabel dibawah ini:

Tabel 1. Data hasil pengukuran arus, tegangan dan daya motor pompa PA - 01 AP001

\begin{tabular}{|c|c|c|c|c|c|c|c|}
\hline $\begin{array}{c}\text { Selang } \\
\text { waktu ke- } \\
\text { (detik) }\end{array}$ & \multicolumn{2}{|c|}{ Ist (Arus starting/Ampere) } & \multicolumn{3}{|c|}{ V (Tegangan) } & \multirow{2}{*}{ P (Daya/kW) } \\
\cline { 2 - 7 } & Fasa R & Fasa S & Fasa T & Fasa R & Fasa S & Fasa & \\
\hline 1 & 831 & 798 & 772 & 394 & 395 & 391 & 198,62 \\
\hline 2 & 177 & 187 & 174 & 397 & 398 & 394 & 131,81 \\
\hline 3 & 242 & 249 & 232 & 397 & 398 & 394 & 133,29 \\
\hline 4 & 328 & 337 & 317 & 398 & 399 & 395 & 157,70 \\
\hline 5 & 328 & 337 & 317 & 398 & 399 & 395 & 159,50 \\
\hline 6 & 334 & 344 & 323 & 400 & 401 & 398 & 158,72 \\
\hline 7 & 1469 & 1500 & 1507 & 374 & 377 & 371 & 393,70 \\
\hline 8 & 276 & 290 & 253 & 402 & 403 & 400 & 153,15 \\
\hline 9 & 280 & 291 & 266 & 402 & 403 & 400 & 159,56 \\
\hline 10 & 285 & 294 & 268 & 402 & 403 & 400 & 160,22 \\
\hline 11 & 287 & 297 & 291 & 402 & 403 & 400 & 163,69 \\
\hline
\end{tabular}

= Nilai arus dan daya mula saat start hubung star

= Nilai perubahan arus, tegangan dan daya dari posisi star ke delta

$=$ Nilai kondisi stabil 
Tabel 2. Data hasil pengukuran arus, tegangan dan daya motor pompa PA - 02 AP001

\begin{tabular}{|c|c|c|c|c|c|c|c|}
\hline \multirow{2}{*}{$\begin{array}{c}\text { Selang } \\
\text { waktu ke }- \\
\text { (detik) }\end{array}$} & \multicolumn{2}{|c|}{ Ist (Arus starting/Ampere) } & \multicolumn{3}{|c|}{ V (Tegangan) } & \multirow{2}{*}{ P (Daya/kW) } \\
\hline 1 & Fasa R & Fasa S & Fasa T & Fasa R & Fasa S & Fasa T & \\
\hline 2 & 627 & 628 & 460 & 159 & 176 & 148 & 39,82 \\
\hline 3 & 805 & 1220 & 881 & 213 & 223 & 215 & 141,20 \\
\hline 4 & 859 & 1342 & 987 & 230 & 247 & 218 & 183,50 \\
\hline 5 & 864 & 1376 & 1046 & 255 & 292 & 264 & 228,33 \\
\hline 6 & 299 & 461 & 351 & 368 & 382 & 363 & 163,51 \\
\hline 7 & 269 & 292 & 264 & 392 & 394 & 388 & 158,70 \\
\hline 8 & 273 & 280 & 265 & 394 & 395 & 391 & 161,46 \\
\hline 9 & 279 & 285 & 272 & 394 & 395 & 391 & 160,78 \\
\hline 10 & 276 & 283 & 269 & 394 & 395 & 391 & 161,27 \\
\hline 11 & 273 & 281 & 266 & 394 & 395 & 391 & 153,05 \\
\hline
\end{tabular}

Tabel 3. Data hasil pengukuran arus, tegangan dan daya motor pompa PA - 03 AP001

\begin{tabular}{|c|c|c|c|c|c|c|c|}
\hline \multirow{2}{*}{$\begin{array}{c}\text { Selang } \\
\text { waktu ke - } \\
\text { (detik) }\end{array}$} & \multicolumn{3}{|c|}{ Ist (Arus starting/Ampere) } & \multicolumn{3}{|c|}{$\mathrm{V}$ (Tegangan) } & \multirow{2}{*}{$\begin{array}{c}\text { P } \\
(\text { Daya/kW) }\end{array}$} \\
\hline & Fasa R & Fasa $\mathrm{S}$ & Fasa T & Fasa $R$ & Fasa $S$ & Fasa T & \\
\hline 1 & 416 & 672 & 500 & 152 & 154 & 158 & 24,47 \\
\hline 2 & 698 & 1091 & 778 & 181 & 189 & 194 & 78,26 \\
\hline 3 & 888 & 1395 & 979 & 205 & 216 & 211 & 125,20 \\
\hline 4 & 973 & 1566 & 1140 & 224 & 239 & 213 & 168,28 \\
\hline 5 & 1030 & 1695 & 1246 & 245 & 266 & 225 & 210,62 \\
\hline 6 & 1118 & 1747 & 1307 & 267 & 292 & 244 & 269,46 \\
\hline 7 & 272 & 375 & 304 & 369 & 382 & 368 & 163,74 \\
\hline 8 & 270 & 294 & 291 & 388 & 391 & 390 & 160,15 \\
\hline 9 & 275 & 300 & 297 & 388 & 391 & 390 & 159,57 \\
\hline 10 & 272 & 296 & 293 & 388 & 391 & 390 & 156,53 \\
\hline 11 & 275 & 300 & 297 & 388 & 391 & 390 & 159,64 \\
\hline
\end{tabular}

Berdasarkan data dan grafik yang diperoleh maka terlihat jelas perbandingan antara nilai arus, tegangan dan daya dengan menggunakan metode Star-Delta dan Soft Starter. Tujuan utama dilakukannya modifikasi pengasutan motor pompa menggunakan metode Soft Starter ialah untuk mengurangi lonjakan nilai arus yang tinggi saat start awal, perbandingan penurunan nilai arus ditunjukkan dalam tabel dibawah ini:

Tabel 4. Perbandingan nilai arus start

\begin{tabular}{|c|c|c|c|}
\hline \multirow{2}{*}{ Metode pengasutan } & \multicolumn{3}{|c|}{ Ist (Arus starting/Ampere) } \\
\cline { 2 - 4 } & Fasa R & Fasa S & Fasa T \\
\hline Star - Delta (PA - 01 AP001) & 831 & 798 & 772 \\
\hline Soft starter (PA - 02 AP001) & 427 & 628 & 460 \\
\hline
\end{tabular}




\begin{tabular}{|l|l|l|l|}
\hline Soft starter (PA - 03 AP001) & 416 & 672 & 500 \\
\hline
\end{tabular}

Sebelum menentukan persentase penurunan terlebih dahulu dihitung nilai $I_{\text {rata-rata }}$ menggunakan rumus berikut:

[14] PA - 01 AP001

$$
\mathrm{I}_{\text {rata-rata }}=\frac{\mathrm{I}_{\mathrm{R}}+\mathrm{I}_{\mathrm{S}}+\mathrm{I}_{\mathrm{T}}}{3}=\frac{831+798+772}{3}=800 \mathrm{~A}
$$

[15] PA - 02 AP001

$$
I_{\text {rata-rata }}=\frac{I_{R}+I_{S}+I_{T}}{3}=\frac{427+628+460}{3}=505 \mathrm{~A}
$$

[16] PA - 03 AP001

$$
\mathrm{I}_{\text {rata-rata }}=\frac{\mathrm{I}_{\mathrm{R}}+\mathrm{I}_{\mathrm{S}}+\mathrm{I}_{\mathrm{T}}}{3}=\frac{416+672+500}{3}=529 \mathrm{~A}
$$

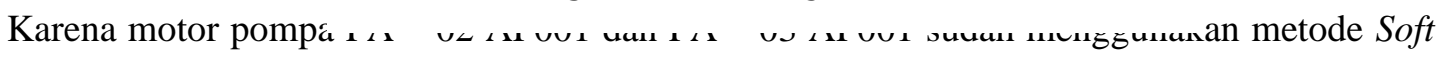
Starter maka didapat $\mathrm{I}_{\text {rata-rata }}$ dari keduanya:

$$
\mathrm{I}_{\text {rata-rata }}=\frac{\mathrm{I}_{\mathrm{PA}-02 \mathrm{AP} 001}+\mathrm{I}_{\mathrm{PA}-03 \mathrm{AP} 001}}{2}=\frac{505+529}{2}=517 \mathrm{~A}
$$

Setelah didapat nilai $\mathrm{I}_{\text {rata-rata }}$ dari hasil perhitungan menggunakan rumus diatas maka dapat dihitung nilai persentase penurunan arus dengan menggunakan rumus berikut ini:

$$
\% \text { Penurunan }=\frac{\text { Nilai penurunan }}{\text { Nilai sebelum penurunan }} \times 100 \%=\frac{517}{765} \times 100 \%=0,67 \%
$$

Melalui hasil perhitungan diatas maka didapatkan persentase efektifitas penggunaan metode Soft Starter dalam menurunkan nilai arus start sebesar 0,67\%, nilai tersebut menunjukkan bahwa prinsip kerja dari metode pengasutan atau start awal motor menggunakan metode Soft Starter.

\section{KESIMPULAN DAN SARAN}

Saat motor dihubung dengan metode Star-Delta nilai lonjakan arus start yang dihasilkan pada saat motor dihubung Star naik mencapai 2 kali lipat dari nilai nominalnya, ketika terjadi perpindahan dari posisi hubung Star ke posisi hubung Delta nilai arus mengalami penurunan sesaat kemudian melonjak naik sampai posisi puncaknya sebesar 3,5 kali lipat dari nilai nominalnya. Ketika motor dihubung dengan metode Soft starter posisi awal pada metode ini ialah hubung Delta, nilai arus saat start naik secara perlahan dan nilai lonjakannya lebih kecil dibandingkan saat menggunakan metode Star-Delta. Hal tersebut disebabkan oleh adanya pengaturan waktu tegangan di dalam rangkaian metode Soft Starter untuk mencapai posisi nominalnya, yaitu selama 10 detik. Perbandingan penurunan nilai lonjakan arus antara metode Star-Delta dan Soft starter ditunjukkan dalam bentuk persentase. Dari hasil perhitungan didapatkan nilai efektifitas penggunaan metode Soft starter dalam menurunkan nilai lonjakan arus saat start adalah sebesar $0,67 \%$. Penelitian ini untuk kedepannya perlu di analisis mengenai nilai torsi pada motor, pengaruh hubungan antara parameter tegangan, arus, daya dan torsi dalam menentukan kualitas kerja motor.

\section{DAFTAR PUSTAKA}

[1] Indrakoeseoema. Koes, Taufiq. Muhammad, "Evaluasi pemasangan Soft Starter pada motor pompa pendingin sekunder PA - 02/03 AP001 RSG-GAS, BATAN, 2017. 
[2] Indrakoeseoma. Koes, Andriyanto. Yayan, Kiswanto, "Pengaruh Soft starter pada arus motor pompa pendingin primer RSG-GAS", Dalam prosiding penelitian dan pengelolaan perangkat nuklir, BATAN, 2011.

[3] Winarto. Febrian Nugroho, Sukmadi. Tedjo, Facta, Muhammad. "Perancangan modul dan perbandingan metode starting dan pengaturan kecepatan motor induksi 3 fasa", Transient, Vol.4 No.1, Maret 2015, ISSN: 2302-9927, 68.

[4] Wijaya. Mochtar, "Dasar-Dasar Mesin Listrik", 2001.

[5] Corporation. Hioki, "Manual book Clamp On Power HiTester 3169-20”, 2014.

[6] Rozi. Fahrul, "Pengujian karakteristik pengasutan motor induksi 3 fasa rotor sangkar menggunakan metode soft starting", 2014. 